\title{
Influence of an Alternating Electric Field on the Coagulation Process and Purifying Effect of $\mathrm{FeCl}_{3}$ Coagulant
}

\author{
Zhibo Shi ${ }^{1,2, *}$, Liyi $\mathrm{Li}^{1}$, and Jie Bai ${ }^{3}$ \\ ${ }^{1}$ School of Electrical Engineering and Automation, Harbin Institute of Technology, Harbin, 150001 \\ ${ }^{2}$ College of Electronic Information and Automation, Civil Aviation University of China, Tianjin, \\ 300300, China \\ ${ }^{3}$ Tianjin Key Laboratory of Civil Aircraft Airworthiness and Maintenance, Civil Aviation University \\ of China, Tianjin, 300300, China \\ *E-mail: zhiboshi2012@126.com
}

doi: $10.20964 / 2019.08 .21$

Received: 11 March 2019 / Accepted: 3 May 2019 / Published: 30 June 2019

\begin{abstract}
In the present study, an experimental study was performed to investigate the influence on the coagulation process and purifying effect of $\mathrm{FeCl}_{3}$ coagulant in river water caused by electric treatment. The variation in water quality parameters under an electric field with different intensities and frequencies was examined in terms of the solution turbidity, particle size distribution, total organic carbon (TOC), chemical oxygen demand (COD) and zeta potential, and then the mechanism of these variations was discussed. The results showed that after the AEF coagulation treatment, the values of turbidity, COD, TOC and zeta potential decreased. The number of larger suspended particles increased. An electric field with a higher intensity or frequency could obtain a better effect on the removal of pollutants. In addition, the main mechanism of the improvement of removal efficiency was due to the electric field force caused by alternating electric fields, which could enhance the collision between charged particles.
\end{abstract}

Keywords: Alternating electric field, Coagulation, $\mathrm{FeCl} 3$ coagulant, Zeta potential, Water quality parameters

\section{FULL TEXT}

(C) 2019 The Authors. Published by ESG (www.electrochemsci.org). This article is an open access article distributed under the terms and conditions of the Creative Commons Attribution license (http://creativecommons.org/licenses/by/4.0/). 